\title{
Laissez Faire and the Clean Development Mechanism: Determinants of Project Implementation in Indian States, 2003-2011*
}

\author{
Patrick Bayer ${ }^{\dagger}$ \\ Johannes Urpelainen ${ }^{\ddagger}$ \\ Alice $\mathrm{Xu}^{\S}$
}

18 March 2014

\begin{abstract}
India is the world's second-largest host of projects implemented under the Kyoto Protocol's Clean Development Mechanism (CDM). There is, however, considerable variation in the distribution of CDM projects implemented across different Indian states. While a large body of literature examines cross-national variation in the implementation of CDM projects, few studies have analyzed the determinants of sub-national variation in different national contexts. Since India has adopted a laissez-faire approach to CDM project implementation, we theorize that profitable climate mitigation opportunities and political stability are two factors that promote CDM project implementation. A quantitative analysis provides empirical support for a set of hypotheses regarding the effects of these variables on project implementation. First, states with a lot of public electricity generating capacity and industrial capital implement more CDM projects than other states. Additionally, project developers rarely propose CDM projects during election years due to high levels of political uncertainty. Since India's liberal approach prevents the central government from using the CDM to promote sustainable development in less developed states, both India and other host countries should develop coordinated national policies to maximize their gains from CDM projects.
\end{abstract}

Keywords: climate policy; international institutions; Clean Development Mechanism; India; sub-national variation.

\footnotetext{
* This paper was written during a research stay funded by an ERP fellowship of the Studienstiftung des deutschen Volkes. Patrick Bayer gratefully acknowledges this generous funding and is thankful for the hospitality of Columbia University. We thank Michaël Aklin, S.P. Harish, and the anonymous reviewers for helpful comments on a previous draft.

${ }^{\dagger}$ Department of Political Science \& Program in International and Area Studies, Washington University in St. Louis. One Brookings Drive. St. Louis, MO 63130, USA.

$\ddagger$ Corresponding author. Department of Political Science, Columbia University. 420 West 118th Street, 712 International Affairs Building. New York, NY 10027, USA.

§ICF International, 1725 Eye Street. Washington, D.C., USA.
} 


\section{Introduction}

The Kyoto Protocol's Clean Development Mechanism (CDM) allows industrialized countries to acquire carbon credits which are generated from emissions reductions in climate mitigation projects in developing countries. As the second-largest user of the CDM, India has played a great part in assisting industrialized countries in securing these cost reductions. Between 2003 and 2011, project developers submitted 2,178 project proposals to the CDM Executive Board. ${ }^{1}$

The use of the CDM across Indian states and over time is highly uneven. Some states, such as Gujarat and Tamil Nadu, have implemented hundreds of CDM projects, while others with equally large populations and land areas, such as Madhya Pradesh, have implemented many fewer. Moreover, the growth in CDM project implementation over time varies across states. Why are there regional differences in the use of the CDM in India?

These questions are important for the emerging literature on sub-national variation in environmental governance (Schreurs, 2008; Andonova and Mitchell, 2010). In the cross-national context, the CDM is concentrated in rapidly industrializing economies, especially China and India. However, it remains unclear if economic development can also explain sub-national variation in CDM project implementation within Indian states. Can theories designed to explain cross-national patterns also explain sub-national variation? Given how many CDM projects are located in a handful of rapidly industrializing states, answering these questions is equally important as explaining variation across host countries.

While the empirical literature on the CDM has analyzed cross-national variation in project implementation (Dechezleprêtre, Glachant, and Ménière, 2008; Castro and Michaelowa, 2011; Dinar et al., 2011), there are few studies that investigate sub-national variation (Bayer, Urpelainen, and Wallace, 2013). Most existing studies on differences in the national governance of the CDM across countries (Ganapati and Liu, 2008; Benecke, 2009; Schroeder, 2009) do not test hypotheses on how national institutions shape sub-national patterns of project implementation. In regard to India, the emerging literature on the CDM includes some studies that analyze CDM projects

\footnotetext{
${ }^{1}$ Data from CDM/ JI Pipeline Database. Available at http://www.cdmpipeline.org. Accessed on May 27, 2012. For our analysis, we consider CDM projects that are registered, waiting for registration, or at the validation stage of the $\mathrm{CDM}$ project cycle.
} 
within the country, but these are either purely descriptive or rely heavily on survey results (Erlewein and Nüsser, 2011; Michaelowa and Purohit, 2007). ${ }^{2}$

In contrast to analyses in the existing research, this study presents findings from a systematic empirical analysis of CDM projects during the 2003-2011 period in 27 Indian states. ${ }^{3}$ Our main argument is that the distribution of CDM projects across India is largely driven by the country's laissez-faire approach to the CDM (Ganapati and Liu, 2008; Benecke, 2009). In contrast to China, where the national government uses the CDM to promote specific economic goals (Schroeder, 2009), such as the development of poor provinces or the transfer of new technologies from abroad (Popp, 2011; Curnow and Hodes, 2009), India does not actively coordinate the implementation of CDM projects across states.

Although we do not replicate the statistical analysis for China in this work, Bayer, Urpelainen, and Wallace (2013) provide an comparable analysis that confirms this difference in experience between the two countries. While the statistical comparison is not exactly identical given the difference in the dependent variable, the logic of the argument is similar, and the article is also based on the same theoretical grounding. Consistent with the idea that Beijing uses the CDM to promote economic development in underprivileged areas, Bayer, Urpelainen, and Wallace (2013) show that Chinese provinces with low per capita income and levels of foreign direct investment receive more technology transfer from the CDM than their wealthier counterparts.

We first argue that India's laissez-faire approach has important implications for sub-national patterns of CDM project implementation. Given India's liberal approach, we expect CDM projects to be concentrated in states with a lot of potential for climate mitigation, as investors are at liberty to search for profitable opportunities. In the absence of a national coordination strategy, CDM projects in India should be located where abatement is cheapest; therefore, states with a lot of mitigation potential are most lucrative CDM hosts. More generally, India's sub-national patterns of CDM project implementation should largely resemble the corresponding cross-national

\footnotetext{
${ }^{2}$ Erlewein and Nüsser (2011) conduct a descriptive analysis of the effectiveness of large hydropower CDM projects in the Indian state of Himachal Pradesh by examining planning documents and carrying out expert interviews. Michaelowa and Purohit (2007) study a sample of 52 CDM project design documents to determine if these documents address additionality.

${ }^{3}$ Other jurisdictions of India did not implement any CDM projects during the study period.
} 
patterns.

Indeed, we find that states with high capacity for public electricity generation and with a lot of industrial capital implement more CDM projects than those that lack these resources. Since electricity and industry are key sources of carbon emissions, this is consistent with the expectation that mitigation potential is central to understanding the distribution of CDM projects within India. On the other hand, our findings show that there is no correlation between private electricity generation capacity and CDM project implementation. Given that electricity generation by the private sector is more productive than the performance of the country's public utilities (Joseph, 2010), it is understandable that public as opposed to private generation capacity increases CDM project implementation. Moreover, India's private electricity generation capacity is a relatively new development because independent power generators were only allowed after the 1991 economic reforms.

In view of India's liberal approach to the CDM, we also hypothesize that investors prefer to avoid implementing new projects during years with high political uncertainty. It is difficult to measure political uncertainty in the sub-national context as a continuous variable. Instead, we construct a simple, binary indicator to capture election years in the states, and use this election years variable to proxy time periods of political uncertainty in the state. Because investors would prefer to avoid political uncertainty that characterizes pre-election and post-election times, CDM project implementation should be lower in a given Indian state during election years than nonelection years. We find that this is the case for renewable energy projects, perhaps because renewable energy projects are more dependent on policies than other energy projects.

This study explains why sub-national variation is as extensive as variation in CDM project implementation across countries. The findings highlight the need for new empirical research at the sub-national level. The approach we use could be applied to an analysis of sub-national variation in other large, developing countries, such as Brazil or South Africa, and to other international institutions that promote environmental projects, such as the Global Environmental Facility. Our study also has important policy implications for developing countries. First, India's laissez-faire approach gives rise to the trend that CDM projects are concentrated in states that are already 
sufficiently industrialized. In this regard, China's more aggressive approach of promoting CDM project implementation in less developed provinces seems more successful than India's hands-off strategy. Second, in the context of institutional differences, it appears that political factors engendered by India's status as a democracy challenge CDM project implementation. India and other rapidly industrializing countries can reap more gains from the CDM if they reassure investors regarding the stability of their climate mitigation policies.

\section{Background, Theory, and Hypotheses}

To set the stage for our empirical analysis, we begin with an overview of the CDM. Then, we provide an account of the CDM in the context of India and derive empirically testable hypotheses.

\subsection{Understanding the Clean Development Mechanism}

The CDM is one of the Kyoto Protocol's "flexible mechanisms" (Article 12). It allows industrialized countries to use Certified Emissions Reduction credits (CERs), which are generated through carbon abatement in developing countries and can be credited against domestic reduction targets. ${ }^{4}$ The CDM scheme promotes "where"-efficiency and takes advantage of lower marginal abatement costs in developing countries (Grubb, 2003). Thus, from an economic perspective, the CDM reduces carbon emissions in a cost-effective manner.

CDM project implementation is characterized by a standard, seven-stage process. ${ }^{5}$ In the first stage, the project participant prepares a Project Design Document (PDD) that details the project's methodologies and expected emission reductions. In the second stage, project participants solicit approval from the Designated National Authority of the host country, confirming that project implementation is voluntary and contributes to the sustainable development of the region. In the subsequent two stages, a nationally accredited Designated Operational Entity (DOE) and the CDM Executive Board conduct a separate review of the design document. If the reviews confirm that the project adheres to the Kyoto Protocol's CDM modalities, the project is registered in the CDM database. The project participants monitor the actual emission reductions in stage 5, and

\footnotetext{
${ }^{4}$ One CER is equivalent to the abatement of one metric ton of carbon dioxide emissions. These credits can be traded and sold to industrialized countries with reduction commitments under the Kyoto Protocol.

${ }^{5}$ For details, see http://cdm. unfccc.int/Projects/diagram.html. Accessed June 11, 2012.
} 
the emissions reduction is verified by the DOE in stage 6. Finally, the CDM Executive Board conducts a final review of the project before it issues CERs to the project participant.

\subsection{Indian Context}

India is frequently listed alongside China and Brazil as one of the most attractive non-Annex I countries for CDM project development. ${ }^{6}$ Especially beginning in the mid-2000s, CDM project development in India reached new heights. Given that the energy sector accounts for more than $85 \%$ of the country's CO2 emissions, a major share of CDM activity in India is, from the beginning, expected to be directed towards reducing emissions from this sector (Markandya and Halsnaes, 2002).

India is a federal system with 28 states and seven Union Territories. Policy formulation is divided between the central and state governments. Because of the organization of the country's federal system, Indian states have substantial political influence in policy areas that target energy and the environment (Benecke, 2009). Lobbying on the part of private enterprises, for one, occurs at the local level. In regard to the CDM, the revenue from the CERs generated by the mechanism are within state interests because they are considered to be a national resource that is created at the local level (Benecke, 2009). In other words, CER revenue is jointly shared by the central and state governments. Overall, Indian policymakers at different levels play an influential role in directing the development of the CDM (Shalini Randeria, 2003).

A critical goal on the country's development agenda is to target poverty alleviation in certain rural communities. In spite of the CDM's capacity to encourage the development of less developed states, while contributing to sustainable development in these regions, the Indian government has not actively channeled CDM project development to the states that need them the most. Sub-national reports conducted by India's Ministry of Environment and Forests document various implementation gaps, institutional rigidities, and state-level differences at play (Benecke, 2009). The National CDM Authority (NCDMA), India's Designated National Authority, evaluates proposed CDM projects according to the probability of successful implementation

\footnotetext{
${ }^{6}$ Non-Annex I countries are mostly developing countries not listed in Annex I of the United Nations Framework Convention on Climate Change. For a complete list of Annex I countries, see http://unfccc.int/parties_and_ observers/parties/annex_i/items/2774.php. Accessed June 11, 2012.
} 
and the degree to which projects meet sustainable development objectives. ${ }^{7}$ Instead of encouraging project implementation in underdeveloped states, the Ministry of Environment and Forests only provides clearance to project participants for the use of forest land. ${ }^{8}$

In contrast to the Chinese government's efforts to direct CDM investment to specific areas that are in line with national priorities (Popp, 2011), the Indian government has adopted a laissezfaire approach to the CDM. In other words, the Indian government takes on a passive role of market facilitation when it comes to the the CDM (Benecke, 2009; Fuhr and Lederer, 2009; Newell, 2009). Specifically, the government refrains from setting up extensive regulation and does not proactively intervene in the promotion of carbon markets in India. The NCDMA places the responsibilities of CDM project implementation largely in the hands of the private sector, and the Authority merely ensures the smooth functioning of the market (Benecke, 2009). In spite of how the Authority "has sufficient human, technical, and financial resources to apply harder control mechanisms, for example, with regard to sustainability assessments, additionality testing, and establishing level-playing fields on regulations," (Benecke, 2009: 366) these regulatory bodies lack the political mandate to use the $\mathrm{CDM}$ as a policy instrument to promote economic development in less developed regions.

There are other, more ingrained factors that help explain the Indian government's liberal approach to the CDM. As a country that inherited various democratic institutions from its precolonial times, democratic politics are a central component of India's CDM regime. Among the Indian public, the NCDMA retains an image as a transparent institution that is open to public consultation (Indian Ministry of Environment and Forests, 2001; Benecke, 2009). The effects of having a higher level of democratic accountability are two-fold.

First, India's central government does not have significant leverage in directing the allocation of CDM projects to different regions. Given the constraints imposed by democracy, the central government simply does not have free reign in interfering with the CDM market. Second, recurring elections are a key feature in a country with sufficiently developed, democratic institutions.

\footnotetext{
${ }^{7}$ See http://www.cdmindia.gov.in/constitution.php. Accessed June 6, 2012.

${ }^{8}$ An assessment of various hydroelectric CDM project development documents proposed for the state of Himachal Pradesh shows that the Ministry's role is limited to the protection of forest land.
} 
Since CDM project developers prefer to avoid political uncertainty, we expect the frequency of elections to affect the pattern of CDM project implementation at the state level. In summary, the democratic institutions in India have a dual effect in allowing market forces to dictate the development of the CDM market and in making elections a determinant of patterns in project implementation.

Despite the laissez-faire approach, the Indian government recently made the CDM project approval process more stringent (Benecke, 2009). Because India has a high number of CDM projects rejected by the CDM Executive Board, the regulatory structure of the CDM in India has been subject to substantial criticism (Newell, 2009). Against this backdrop, the relevant government bodies, many of which are at the state level, were obliged to respond accordingly. Benecke (2009) finds that the NCDMA has been particularly concerned with the extent to which proposed projects fulfill the sustainability criteria. He notes that the NCDMA has also embraced a more rigorous evaluation of project additionality and baseline assessment, a task that usually falls under the domain of the Designed Operational Entities (Benecke, 2009).

While India's approach to the CDM is generally liberal, the public sector has traditionally played a key role in the electricity sector. In India, state utilities cannot provide reliable power service, because regulation of electricity generation by the public sector has been plagued with ongoing power theft by customers, corruption, and an artificially decreased pricing structure (Joseph, 2010). Tongia (2003) confirms that the Indian power sector is beset with theft and bureaucratic inefficiencies, citing a loss of 5 billion dollars per year. The value, constituting more than one percent of the country's GDP, is a generous underestimate, for the losses would be much greater if state governments did not spend around two billion dollars in cross subsidies, grants, and soft loans to alleviate the existing problems (Tongia, 2003). In response to the failed attempts to reform public sector electricity generation, industrial consumers have resorted to private, on-site generation to secure stable electricity provision (Joseph, 2010; Mathy, Hourcade, and de Gouvello, 2001). This recent trend has resulted in a "dual-track economy" (Joseph, 2010: 503) with coexisting public and private electricity generation.

India's policies to support renewable energy also have a great impact on patterns in CDM 
project implementation. While national policies that support renewable electricity generation exist, there is considerable variation in support for renewable electricity at the sub-national level. In April 2010, for example, 17 of the 27 Indian states had established a Renewable Portfolio Obligation (Arora et al., 2010: 25-26), which would increase the profitability of renewables. This policy along with many others have had a large impact on the profitability of climate mitigation under the CDM in India. Therefore, it is important to account for the political and economic characteristics of different states.

We expect CDM project development to exhibit unequal distribution across India, with projects concentrated in the states that are highly industrialized. As Figure 1 shows, the states of Maharashtra and Tamil Nadu, two states that are among those with the highest GDP, are shown as having the highest number of CDM projects. In contrast, states in the northern and eastern regions, such as Sikkim and Andhra Pradesh, have much lower GDP and also much fewer CDM projects. In his assessment of the extent to which CDM projects in India contribute to the socioeconomic component of the country's sustainable development objectives, Sirohi (2007) finds that the government's laissez-faire approach has resulted in a CDM market that is dominated by underlying business interests. Because market forces dictate CDM project implementation, project development is rarely directed towards the rural poor. In other words, CDM project developers choose project locations to maximize profits.

[Figure 1 about here.]

\subsection{Hypotheses}

Building on the overview provided in the last two sections, we arrive at several empirically testable hypotheses. The hypotheses relate climate mitigation potential and political uncertainty to the implementation of CDM projects. Since mitigation potential is commonly analyzed in the cross-national literature (Castro and Michaelowa, 2011; Dinar et al., 2011), it is natural to expect it to shape project implementation under India's liberal policy. Because political uncertainty has not been analyzed in past studies, our results can inform future studies of the politics of the $\mathrm{CDM}$ in other political contexts. All hypotheses are formulated such that key factors, such as 
state population, are controlled for in the empirical analysis.

Using state-year as the unit of analysis, we examine the role of sub-national state characteristics on CDM project implementation. More specifically, we hypothesize that public electricity generating capacity and the amount of industrial fixed capital, as indicators of mitigation potential, increase CDM project implementation. As to political uncertainty, we expect the implementation of CDM projects to decrease during election years.

First, we expect that electricity generation has an effect on CDM project implementation. In practice, many CDM projects aim to reduce carbon emissions from specifically electricity generation. ${ }^{9}$ There are three reasons for this emphasis on electricity generation in the CDM. First, the demand for carbon credits from CDM projects is highest among electricity generating utilities from industrialized countries. In the European Union's Emissions Trading Scheme (EU ETS), for example, the energy sector alone accounts for more than $60 \%$ of all regulated emissions in Europe (Ellerman and Buchner, 2007). Although the CDM does not specify any sector-specific regulations, energy utilities are likely to invest in electricity generating CDM projects because of the existing informational and technological experience and expertise. Second, electricity generation in itself is highly carbon-intensive, and thus has substantial potential for carbon reductions. Finally, less developed countries often use inferior, or outdated, technologies to generate electricity. Hence, the existing inefficiencies make investment in electricity generating CDM projects very attractive.

As discussed above, the distinction between private and public electricity generating capacities is crucial in the Indian context. To empirically explore this difference, we estimate the effects of private and public electricity generating capacity separately on the number of CDM projects. Following Joseph's (2010) analysis, the unprecedented rise in installed capacity of privately owned electricity generation units is the industrial sector's response to unreliable electricity production on the part of state-owned units. While inefficiencies in the public sector remain high, the newly established private electricity sector has a much lower level of capacity, is less prone to corruption, and is more efficient. Since CDM investment is most profitable when ineffi-

\footnotetext{
${ }^{9}$ In our total sample that includes renewable energy and energy efficiency projects, 1,921 out of 2,178 projects or $88 \%$ of our data are related to energy production.
} 
ciencies are large, we expect that generation capacity in the more efficient private sector does not affect the number of CDM projects, while that in the inefficient public electricity generation has a positive association with the number of CDM projects. The explanation presented leads to the two hypotheses that follow:

Hypothesis 1 (private electricity generating capacity and project implementation). A state's private electricity generation does not have an effect on CDM project implementation in that state at a given time.

Hypothesis 2 (public electricity generation and project implementation). The larger a state's public electricity generation, the higher is the number of CDM projects implemented in that state at a given time.

In addition to the discrepancy between private and public electricity generating capacity, we hypothesize that states with a developed, industrial capital base should have a higher number of CDM projects. A higher level of industrial, fixed capital implies greater capacity for industrial activity, and a rise in industrial activity, in turn, results in higher levels of carbon emissions. Industries, such as cement, ceramics, iron, steel, or glass, are energy- and carbon-intensive in comparison to those in the agriculture or services sector. Therefore, a large industrial capital base indicates that there is high potential for emissions reductions. The number of CDM projects in a given Indian state is likely to be higher in industrialized states than in those with minimal industrial development that rely heavily on agricultural production.

Hypothesis 3 (industrial capital and project implementation). The larger a state's industrial capital base, the higher the number of CDM projects implemented in that state at a given time.

This is not to say that CDM investments under high levels of industrial capital are necessarily driven by specific plans for carbon abatement. It is more plausible that the investments reflect opportunities afforded by industrial production and growth, especially given the volatility of the carbon credit price in international markets. We do not make claims about the priority ordering of the CDM in the state government's planning, but instead focus on the relationship between industrial capital and opportunities for CDM projects more generally.

Finally, India's laissez-faire approach implies that the lack of political mandate to develop the CDM market may hinder project implementation. India does not have a political commitment to 
strategically promote CDM in underdeveloped states. Since a considerable share of total CDM projects is large-scale projects that involve wind farms or hydroelectric dams, investments are only worthwhile given stable political and economic conditions. ${ }^{10}$ Since the implementation of a CDM project may require a lot of time and political difficulties at any time during that period can reduce the profitability of the effort, investors rationally anticipate electoral uncertainty and try to avoid initiating projects at election time.

For example, consider India's largest CDM project (CDM5760), a project approved in 2009 that supports methane capture from mining activities in West Bengal. ${ }^{11}$ This project seeks to reduce more than 83 million tons of $\mathrm{CO} 2$ emissions over a period of ten years. ${ }^{12}$ Clearly, firms would not be willing to invest in such large-scale projects when the political environment is uncertain. In election years, politics are inherently subject to change. New governments could be elected. Existing, favorable policies, such as subsidies or tax exemptions, could be reversed if governmental priorities change during election years. Instead of implementing CDM projects in election years, investors are inclined to postpone investment decisions until the political climate is stable once again. Moreover, the electoral cycle could create administrative difficulties that could slow down the approval process of CDM proposals on the part of state government agencies. Such potential difficulties during election season may prompt investors to postpone the initiation of CDM registration procedures. The theoretical explanation provided leads to the following hypothesis:

Hypothesis 4 (state elections and project implementation). During election years, the number of CDM projects implemented in a state is lower than that during other years.

In the section that follows, we describe how we test the four hypotheses that link private and

\footnotetext{
${ }^{10}$ Approximately one third of the CDM projects in our sample are classified as large-scale projects, while the rest is considered small-scale. In accordance with the official CDM guidance document, we classify projects as small based on the used methodology. Specifically, we use methodologies with the prefix, "AMS," to categorize projects as small. See http://www.cdmpipeline.org/publications/GuidanceCDMpipeline.pdf. Accessed June 11, 2012.

${ }^{11}$ For further details, see the project design document at http://cdm.unfccc.int/filestorage/Z/H/E/ ZHE76BG0Q4L01XTYUV9F85WIJPCMRA/PDD\%20GEECL.pdf?t=MzB8bTR3NmIxfDDK9-54G1mtewm0XEyf0Iek. Accessed May $31,2012$.

${ }^{12}$ The total amount of $\mathrm{CO} 2$ emissions reductions of this single project over its entire ten year lifespan matches almost CO2 emissions of the Philippines in a single year like 2008. See the World Development Indicators for emissions data at http://data.worldbank.org/indicator/EN. ATM. CO2E. KT. Accessed May 31, 2012.
} 
public electricity generating capacity, the amount of industrial, fixed capital, and election years with CDM project development across Indian states.

\section{Research Design}

For our empirical analysis, we collect data on the number of CDM projects in 27 Indian states for the years 2003-2011. ${ }^{13}$ The CDM data is provided by the CDM Pipeline ${ }^{14}$ in units of stateyear. In total, the dataset includes 231 observations and 2,178 CDM projects, so we have a balanced panel. ${ }^{15}$ To conduct the analysis, we estimate negative binomial count regressions with random effects. The purpose of our analysis is to examine how variation in the values of four key explanatory variables (i.e., private and public electricity generating capacity, industrial fixed capital, and election years) predicts the number of new CDM projects implemented in a given year in each state.

\subsection{Dependent Variable}

The dependent variable in our analysis is the number of new CDM projects that are available from the official CDM/JI Pipeline Database for a specific year in each of the 27 Indian states. As Table 1 shows, this count varies considerably across states and over time. While there are very few CDM projects in the earlier years (i.e., only one in 2003 and nine in 2004), the number rises dramatically during the later years (i.e., 362 in 2010 and 391 in 2011). In addition to variation across time, there is considerable variation across states. While the state of Maharashtra holds the record for implementing 55 new projects in 2007, Arunachal Pradesh consistently does not implement any projects in all the years except 2007 (i.e., when it has one project) and 2011 (i.e., when it has two projects). Projects are also clustered by region, with more than 700 projects located in the southern regions and only 66 implemented in the northeastern region.

[Table 1 about here.]

\footnotetext{
${ }^{13}$ Overall, in India, there are 35 sub-national units, 28 states, and 7 Union Territories. Since we lack non-zero CDM project data for all Union Territories except Delhi (Andaman and Nicobar Islands, Chandigarh, Dadra and Nagar Haveli, Daman and Diu, Lakshadweep, and Pondicherry) and for two states (Mizoram and Nagaland), our sample consists of only 27 sub-national units. See http://india.gov.in/knowindia/state_uts.php. Accessed May $31,2012$.

${ }^{14}$ See http://www . cdmpipeline.org. Accessed December 31, 2011.

${ }^{15}$ Again, it bears mentioning that our dataset includes all CDM projects that are either registered, waiting for registration, or at the validation stage.
} 
To account for the non-normal distribution of the dependent variable in our statistical analysis, we use a negative binomial count model. An alternative approach used with conventional regression models is to construct the dependent variable, the total amount of $\mathrm{CO} 2$ emissions reductions in a given state-year, as a continuous variable. The approach is inferior to our count data approach for three reasons. First, around two-thirds of the CDM projects in our sample are classified as small projects. Using total abatement as a dependent variable would bias the analysis towards large-scale projects. Second, emissions reductions are not yet realized for most projects, but are only projected quantities. Hence, emissions reduction measures are subject to high uncertainty compared to the undisputed measure of counts for implemented projects. Third, as shown in the supplementary appendix, the number of CDM projects is highly correlated with the expected total number of Certified Emissions Reductions by 2020. In our sample, the five states with the highest numbers of CDM projects (i.e., Tamil Nadu, Maharashtra, Gujarat, Karnataka, and Rajasthan) account for $58 \%$ of the sample, and similarly, comprise $42 \%$ of expected carbon emissions reductions by 2020.

Taking into account the systematic differences between renewable and non-renewable CDM projects, we conduct a separate, empirical analysis on renewable projects (1,426 projects) and on non-renewable projects (752 projects). This disaggregation is justified because our explanatory variables may affect CDM allocation differently due to geographical heterogeneity across Indian states. Long rivers, strong winds, and many hours of sunshine make hydropower, wind, or solar energy projects more likely in certain regions more than in others. Non-renewable energy projects, on the other hand, are not affected by these geographical characteristics. Because pooling data would prevent us from accounting for these differences in the analysis, we test our hypotheses separately for renewable and non-renewable projects. The results of the analysis are discussed below.

\subsection{Independent Variables}

To test the four hypotheses, we first add an explanatory variable to operationalize each state's electricity generating capacity. To do this, we collected data on the installed capacity (megawatts) of Indian power utilities. The data is collected from the Annual Reports provided by the Indian 
Ministry of Power. ${ }^{16}$ The reports allow us to also disaggregate installed capacity by ownership type. Specifically, we disaggregate the variable of electricity generation capacity into publicly and privately owned utilities. This allows for a more meticulous analysis that differentiates between state- and market-based investment choices. Since both variables are highly skewed to the right, we logarithmize both variables before entering them to into our statistical model. ${ }^{17}$

Our third hypothesis is that a larger industrial capital base is more conducive to CDM investment in a given state-year. We measure this variable with data from the Annual Survey of Industries, which is published by the Indian Ministry of Statistics and Programme Implementation since 1998. ${ }^{18}$ This survey provides data on fixed capital by state, a variable measured in million rupees. To account for the non-normal distribution, we take the logarithm of this variable. We also apply linear extrapolation for years after 2010 to avoid losing the 391 CDM projects that were implemented in 2011. ${ }^{19}$

To operationalize our hypothesis on the influence of elections, we code an election year variable. ${ }^{20}$ This is a binary indicator that scores one for each year in which elections take place in an Indian state and zero otherwise. ${ }^{21}$ Overall, there are 28 state-level elections in our sample for the years 2003-2011. During this time period in India, more than three state-level elections are called per year.

\subsection{Control Variables}

While we prefer a simple econometric specification, we include additional models with four statelevel control variables to check for the robustness of our results. First, we include a logarithmic measure of total population size to capture pure scale effects. ${ }^{22}$ Densely populated states are

\footnotetext{
${ }^{16}$ See http://www.powermin.nic.in/reports/annual_report.htm. Accessed April 24, 2012.

${ }^{17}$ Distributions of privately and publicly owned electricity generating capacities can be found in the supplementary appendix.

${ }^{18}$ See http://mospi.nic.in/mospi_new/upload/asi/ASI_main.htm?status=1\&menu_id=88. Accessed May 13, 2012.

${ }^{19}$ The supplementary appendix provides a histogram showing the distribution of the industrial capital base variable. To account for the fact that the capital base needs to be renewed over time, we also estimate regression models with both the level and the annual net change in the capital base included, without any consequences of our main results.

${ }^{20}$ See http://eci.nic.in/eci_main1/ElectionStatistics.aspx. Accessed June 6, 2012.

${ }^{21}$ To avoid bias from potential anticipation and backlog effects from elections called at the beginning or the end of a year, we also estimate models with pre- and post-election year dummies, without any changes to our results.

${ }^{22}$ Population data come from the census of the Office of the Registrar General of India. See http:// planningcommission.nic.in/data/datatable/0904/tab_169.pdf. Accessed May 20, 2012.
} 
more likely to attract more CDM projects simply because they are larger. Since population data is only available for the years 2001 and 2011, we use linear interpolation for this variable to increase the number of observations for our population variable. Controlling for size effects is more important than the concern that interpolation may not be an accurate measure of population size in a given state-year.

Second, we control for GDP per capita, a measure in units of thousand rupees at 2005 constant prices. $^{23}$ The inclusion of this control variable is necessary because wealthier states may offer a more attractive investment environment. Since industrial capital is a source of wealth, the control variable allows us to avoid conflating the effects of industrial capital with the effects of wealth. It could also be the case that in states with a higher level of net wealth, the cheapest abatement opportunities may have already been realized, discouraging CDM project implementation in these states. Although the direction of the effect of GDP per capita on CDM project implementation is unclear, we control for the effects of state income. To account for the asymmetric distribution, the logarithm of the GDP per capita variable is used.

Third, we add economic growth as a variable to capture change in economic performance over time. We construct this control variable as the percentage change in GDP per capita relative to that of the previous year, and the data comes from the same sources as those for the nominal GDP per capita variable. Controlling for economic growth is important because states with higher levels of economic growth can obtain more CDM projects than those with slower rates of growth. To avoid conflating the impact of economic growth on CDM project implementation with the systematic effects of our hypotheses, we add economic growth to only select econometric specifications.

Fourth, we control for each state's level of public debt as a percentage of the state's GDP. ${ }^{24}$ Public debt measures how well a state is managed. In other words, it is indicative of the stability of the CDM investment environment provided by the state. Including a public debt control allows us to account for state-year differences in economic governance across Indian states. The

\footnotetext{
${ }^{23}$ Data are from the Directorate of Economics Statistics of the respective state governments. See http:// planningcommission.nic.in/data/datatable/0904/tab_109.pdf. Accessed April 25, 2012.

${ }^{24}$ Data are from the Databook for DCH. See http://planningcommission.nic.in/data/datatable/0904/tab_115. pdf. Accessed May 20, 2012.
} 
supplementary appendix provides histograms illustrating the distribution of all our control variables.

To account for the effects of time trends, all our models include year fixed effects. The year indicators also account for the electoral victory of the Indian National Congress over BJP in 2004. To account for regional differences arising from geographic heterogeneity and other unobserved state characteristics that may affect the distribution of CDM project implementation, we use zonal (i.e., region) fixed effects. ${ }^{25}$ For this, we classify all Indian subnational units under six Zonal Councils, as established in the 1956 States Reorganization Act and the 1972 North Eastern Council Act. ${ }^{26}$

Table 2 shows the summary statistics for all our dependent, independent, and control variables. We find that there is considerable variation across observations in our panel dataset. Most importantly, the dependent variable is far from being normally distributed. Instead, it is highly skewed with a mean of 9.33 , a standard deviation of 13.92, and minimum and maximum values of zero and 80 . Our negative binomial count model can account for this data structure.

\section{[Table 2 about here.]}

We present a correlation matrix of all our variables in Table 3. The bivariate correlations show two remarkable facts. First, electricity generating capacity, both private and public, and industrial capital base are positively correlated with our dependent variables of total, renewable, and non-renewable CDM projects; in contrast, the election year variable has a negative influence. All these effects are thus in line with our expectations. Second, the private and public electricity generation variables are significantly correlated, but only at a level of $r=+0.446$.

\footnotetext{
${ }^{25}$ In a robustness check, we also estimate our main models with state fixed effects instead of regional ones, without any changes to our findings.

${ }^{26}$ Specifically, we have the Northern Zonal Council (Chandigarh, Delhi, Haryana, Himachal Pradesh, Jammu and Kashmir, Punjab, Rajasthan), the Central Zonal Council (Chhattisgarh, Madhya Pradesh, Uttarakhand, Uttar Pradesh), the Eastern Zonal Council (Bihar, Jharkhand, Orissa, and West Bengal), the Western Zonal Council (Dadra and Nagar Haveli, Daman and Diu, Goa, Gujarat, Maharashtra), the Southern Zonal Council (Andhra Pradesh, Karnataka, Kerala, Pondicherry, and Tamil Nadu), and the North Eastern Council (Arunachal Pradesh, Assam, Manipur, Meghalaya, Mizoram, Nagaland, Sikkim, and Tripura). The Indian Union Territories Andaman and Nicobar Islands and Lakshadweep are not part of any of India's six official Zonal Councils, so they are not listed in Table 1. This classification comes from the Ministry of Home Affairs of the Indian Government. See http://www.mha.nic.in/uniquepage.asp?ID_PK=470 for additional information. Accessed June 5, 2012.
} 
[Table 3 about here.]

\subsection{Statistical Model}

We estimate a negative binomial count model with random effects. This is a two-level model that allows the distribution of the error term to vary across the 27 subnational units in our sample. A series of likelihood ratio tests confirms that random effects are justified, given that the null hypothesis of identical error distributions across Indian states can be rejected. We also use the Vuong test to check for zero inflation (Vuong, 1989). Using population and year as the zero-inflation variables, the test statistic allows us to reject the null hypothesis of zero inflation. We cannot include a lagged dependent variable in the estimation since the estimation is only consistent under exponential growth in the dependent variable (Brandt et al., 2000).

\section{Results}

We first report findings from our main model with the total CDM project count as the dependent variable. Then, we present the results from when we disaggregate the analysis by project type, using the number of renewable and non-renewable CDM projects as dependent variables. For our key findings, we present substantive effects.

\subsection{Main Findings}

Table 4 shows regression results for five count models with random effects, including all CDM projects hosted by the 27 Indian states in our sample. While our first model only includes our four explanatory variables (i.e., private and public electricity capacity, fixed capital base, and an election year dummy), models (2)-(5) differ with respect to the set of control variables. We extend our set of control variables from only population (model (2)) to GDP per capita (model (3)), economic growth (model (4)), and public debt (model (5)). As discussed above, all our models have year fixed-effects and zonal fixed-effects.

For our main results, we find a consistent pattern: industrial capital base has a positive and highly significant effect on CDM allocation, while political uncertainty, operationalized by our

election year dummy, decreases the number of implemented CDM projects. Public electricity generating capacity consistently has a positive effect on CDM project implementation across all 
models, though the coefficient is only statistically significant in one. This lack of robustness could reflect the fact that some public generation capacity, such as large hydroelectric facilities, may not offer opportunities for the CDM. In stark contrast, the coefficients for private electricity generation capacity are tiny and never statistically significant. This not only sheds light on the systematically different effects of state-based compared to market-based electricity generation in India, but also provides tentative support to our political-economic explanation for this finding. Higher inefficiencies in the public electricity sector allow for more profitable investment in climate mitigation, and thus CDM project implementation increases with increased generation capacity in state-owned utilities.

\section{[Table 4 about here.]}

Figure 2 illustrates the substantive effects for our main explanatory variables from model (1) (King, Tomz, and Wittenberg, 2000). All simulations of these substantive effects are based on 1,000 draws from a multivariate normal distribution. For continuous variables, we consider a change from the mean to one standard deviation above the mean, while for the election year dummy we increase the binary indicator from zero to one.

\section{[Figure 2 about here.]}

In line with our regression results, the strongest marginal effect is detected for industrial capital base. On average, a one standard deviation increase above the mean increases the number of CDM projects by 6.67, with 19.30 and 0.43 as lower and upper bounds, respectively. The marginal effect of public electricity generating capacity is only slightly smaller (average increase of 4.74), with somewhat larger confidence bounds of 16.87 and -1.31 . The expected effect of private electricity generation capacity is almost exactly zero, and thus also not statistically significant. Finally, election years decrease the mean number of CDM projects by -1.69 , where -0.19 and -4.68 are the boundaries of the $95 \%$ confidence interval.

In summary, our statistical analysis confirms our four hypotheses. In our sample of 27 Indian states and 2,178 CDM projects, higher public electricity generating capacity and a larger industrial capital base increase the number of CDM projects implemented. Political uncertainty, cap- 
tured by the election year variable, negatively affects investment conditions, and thus, reduces the number of hosted CDM projects. Consistent with this hypothesis, an additional analysis shows that the negative effect of political uncertainty is even exacerbated in those election years in which political competition is high, as indicated by a comparatively small winning margin. Our analysis also points to systematic differences between private and public electricity generating capacity. This finding deserves particular attention that merits future research. From a cross-country perspective, it is interesting to examine if this difference is equally applicable to other contexts as well.

To examine the robustness of our results, we conduct five additional tests ${ }^{27}$. First, we run the negative binomial models with random effects using three different independent variables: electricity transmission and distribution losses (\%) and two types of controls for corruption, that is the number of corruption cases and data from Transparency International's (2005) corruption index for India. ${ }^{28}$ The results remain virtually unchanged. Second, we estimate our models without the observations for the year 2011. Many of the independent variables have observations for 2011 that were derived from linear extrapolation; for example, fixed capital, one of our main explanatory variables, is extrapolated beyond 2010. By excluding the year 2011 from the analysis, we can confirm our results to be robust without that specified year. Indeed, the results are generally stronger when the year 2011 is excluded. Third, as CDM project allocation is shaped by geographical and physical considerations, that is renewable energy potential, in particular, we control for renewable potential from solar, hydroelectricity, and wind sources, without any changes to our main findings. Fourth, we include a control variable that accounts for CDM promotion policies at the subnational level. Finally, we examine whether party cohesion between the federal government and state-level governments matters for the distribution of CDM projects across Indian states. Our results remain unaffected in both additional checks, as neither

\footnotetext{
${ }^{27}$ All estimation results can be found in the supplementary appendix.

${ }^{28}$ Data on state-level transmission and distribution losses (\%) is made available for the years 2002-2008 by the Central Electricity Authority's General Review 2007, 2008. We use the logarithm of this variable, and extrapolate the data beyond 2008 to allow analysis for CDM projects implemented during later years. Data on state-level corruption cases, or total cases brought in for investigation, is available from 2000-2009 and is taken from the Crime in India annual reports collated by the PRS Legislative Research. See http://ncrb.nic.in/ciiprevious/main.htm. Accessed May 20, 2012. The logarithm of total corruption cases is used, and the data is also extrapolated.
} 
promotion policies nor partisanship is found to influence CDM allocation.

\subsection{Disaggregation by Project Type}

In Table 5, we show the regression results for the same five count models as before, but only considering the 1,426 renewable projects in our sample. We disaggregate our analysis to explore differences across project types, i.e., across renewable and non-renewable CDM projects. While the positive effects that we find for public electricity generating capacity and industrial capital base attenuate in our reduced sample, the negative effect of political uncertainty on renewable CDM project remains strong. ${ }^{29}$

[Table 5 about here.]

To examine the impact of our explanatory variables on non-renewable CDM project allocation, we re-estimate our five negative binomial count models for 752 non-renewable projects in our sample. Table 6 shows the estimation results. Compared to our previous findings, for nonrenewable CDM projects, political uncertainty does not seem to matter, at least not at statistically significant levels. However, a state's industrial capital base and public electricity generating capacity increase CDM project implementation in a given state-year. ${ }^{30}$

[Table 6 about here.]

In summary, we find a consistent pattern in our empirical analysis. In the full sample, public electricity generating capacity and fixed industrial capital base have a positive effect on the number of implemented CDM projects. In contrast, political uncertainty discourages the allocation of CDM projects. Interestingly, the noted effects vary according to project type. In the sample with only renewable CDM projects, the election year effect is the only explanatory variable with a statistically significant coefficient. In line with our argument on political uncertainty, it is not unlikely to assume that renewable energy projects are more dependent on political support. The development of new technologies and the deployment of (decentralized) renewable energy

\footnotetext{
${ }^{29}$ See the supplementary appendix for the substantive effects plots.

${ }^{30}$ See the supplementary appendix for the substantive effects plots.
} 
production are commonly subsidized by governments. This may, in part, explain why renewable CDM project implementation is more responsive to political uncertainty than non-renewable project development.

In the sample with only non-renewable energy projects, public electricity generating capacity has a limited positive effect on project count, and the coefficients are not statistically significant. Additionally, fixed capital has a strong, positive association with CDM project implementation. The correlation matrix in Table 3 above shows there are stronger correlations in size between electricity generating capacity and capital base with non-renewable energy projects than with renewable ones. Since the correlation between the number of renewable energy projects and project size $(r=+0.952)$ is much higher than that between the number of non-renewable energy and small projects $(r=+0.578)^{31}$, the larger average project size of non-renewable projects may explain why public electricity generating capacity and the fixed capital base are more important for this type of project.

\section{Conclusion}

In India, thousands of CDM projects have reduced carbon dioxide emissions at a low cost. Due to the central government's liberal approach to the CDM, project implementation in India has been largely driven by business opportunities. At the sub-national level, this has produced considerable variation across states and over time. In this article, we have analyzed the determinants of CDM project implementation in Indian states from 2003-2011. Our main premise is that India's liberal approach to the CDM emphasizes the importance of climate mitigation opportunities, while increasing the salience of political factors. In contrast to China, India does not use the CDM to promote economic development in less developed areas.

Our findings corroborate these hypotheses. Both public electricity generation and industrial capital have large, positive effects on CDM project implementation. This is consistent with the central role of mitigation potential in explaining the distribution of CDM projects under India's liberal policy framework. However, private electricity generation is not associated with CDM project implementation. A potential explanation for this null finding is the public sector's domi-

\footnotetext{
${ }^{31}$ The difference between the correlation coefficients is highly statistically significant with $p<0.000$.
} 
nance in Indian electricity generation and the private sector's superior efficiency relative to that of the public sector. Finally, CDM projects are rarely proposed during election years.

Our findings emphasize the need for more research on sub-national variation in climate policy. Several researchers have found that sub-national variation is equally, if not more, important than cross-national variation (Schreurs, 2008; Andonova and Mitchell, 2010). However, there are few quantitative studies that explain sub-national variation within large countries like India. Further empirical analysis on variation at the sub-national level promises large payoffs. For example, scholars should investigate how the importance of mitigation potential as a covariate of CDM projects within countries depends on national institutions. Our findings concerning the importance of sub-national elections in India also highlight the importance of incorporating sub-national politics into models of CDM implementation within countries. At the same time, we recognize that, especially in the early years of the CDM, the methodology for establishing a baseline for business-as-usual emissions has suffered from certain problems. Therefore, it would be useful to evaluate the environmental quality of India's CDM projects.

For policymakers in India and elsewhere, our study also offers some useful suggestions. While India's laissez-faire approach to the CDM can be justified as attractive to project developers, it carries the hidden cost of neglecting underdeveloped states. Without centralized coordination, the CDM cannot allow the federal government to promote sustainable development in states that would need it the most. While China's policymakers have implemented policies that allow the country to use the CDM to promote economic development in the country's underdeveloped Western provinces (Schroeder, 2009), India has not adopted this strategy. India and other developing countries can maximize the developmental benefits of the CDM by adopting coordinated national policies that promote project implementation in less developed areas. For example, national governments could offer incentives to CDM project developers that locate their projects in less industrialized regions. Similarly, national governments could reduce the transaction costs of project implementation in less developed areas by investing in capacity building. For example, this strategy could build on lessons from China's CDM Service Center model (Schroeder, 2009: 380). 


\section{References}

Andonova, Liliana B., and Ronald B. Mitchell. 2010. "The Rescaling of Global Environmental Politics." Annual Review of Environment and Resources 35 (1): 255-282.

Arora, D.S., Sarah Busche, Shannon Cowlin, Tobias Engelmeier, Hanna Jaritz, Anelia Milbrandt, and Shannon Wang. 2010. "Indian Renewable Energy Status Report: Background Report for DIREC 2010." National Renewable Energy Laboratory, NREL/TP-6A20-48948.

Bayer, Patrick, Johannes Urpelainen, and Jeremy Wallace. 2013. "Who Uses the Clean Development Mechanism? An Empirical Analysis of Projects in Chinese Provinces." Global Environmental Change 23 (2): 512-521.

Benecke, Gudrun. 2009. "Varieties of Carbon Governance: Taking Stock of the Local Carbon Market in India." Journal of Environment and Development 18 (4): 346-370.

Brandt, Patrick T., John T. Williams, Benjamin O. Fordham, and Brian Pollins. 2000. “Dynamic Modeling for Persistent Event-Count Time Series." American Journal of Political Science 44 (4): 823-843.

Castro, Paula, and Axel Michaelowa. 2011. "Would Preferential Access Measures Be Sufficient to Overcome Current Barriers to CDM Projects in Least Developed Countries?" Climate and Development 3 (2): 123-142.

Curnow, Paul, and Glenn Hodes. 2009. Implementing CDM Projects: A Guidebook to Host Country Legal Issues. Roskilde, Denmark: UNEP Risoe Centre.

Dechezleprêtre, Antoine, Matthieu Glachant, and Yann Ménière. 2008. "The Clean Development Mechanism and the International Diffusion of Technologies: An Empirical Study." Energy Policy 36 (4): 1273-1283.

Dinar, Ariel, Shaikh Mahfuzur Rahman, Donald F. Larson, and Philippe Ambrosi. 2011. "Local Actions, Global Impacts: International Cooperation and the CDM." Global Environmental Politics 11 (4): 108-133.

Ellerman, Denny A., and Barbara K. Buchner. 2007. “The European Union Emissions Trading Scheme: Origins, Allocation, and Early Results." Review of Environmental Economics and Policy 1 (1): 66-87.

Erlewein, Alexander, and Marcus Nüsser. 2011. "Offsetting Greenhouse Gas Emissions in the Himalaya: Clean Development Dams in Himachal Pradesh, India." Mountain Research and Development 31 (4): 293-304.

Fuhr, Harald, and Markus Lederer. 2009. “Varieties of Carbon Governance in Newly Industrializing Countries." Journal of Environment and Development 18 (4): 327-345.

Ganapati, Sukumar, and Liguang Liu. 2008. "The Clean Development Mechanism in China and India: A Comparative Institutional Analysis." Public Administration and Development 28: 351362.

Grubb, Michael. 2003. "The Economics of the Kyoto Protocol." World Economics 4 (3): 143-189. 
Indian Ministry of Environment and Forests. 2001. "India: State of the Environment 2001." Joint Report with UNEP and TERI.

Joseph, Kelli L. 2010. “The Politics of Power: Electricity Reform in India." Energy Policy 38 (1): 503-511.

King, Gary, Michael Tomz, and Jason Wittenberg. 2000. "Making the Most of Statistical Analyses: Improving Interpretation and Presentation." American Journal of Political Science 44 (2): 341-355.

Markandya, Anil, and Kirsten Halsnaes. 2002. Climate Change and Sustainable Development Prospects for Developing Countries. London, UK: Earthscan Publications.

Mathy, Sandrine, Jean-Charles Hourcade, and Christophe de Gouvello. 2001. "Clean Development Mechanism: Leverage for Development?" Climate Policy 1 (2): 251-268.

Michaelowa, Axel, and Pallav Purohit. 2007. "Additionality Determination of Indian CDM Projects: Can Indian CDM Project Developers Outwit the CDM Executive Board." Climate Strategies Discussion Paper CDM-1.

Newell, Peter. 2009. "Varieties of CDM Governance: Some Reflections." Journal of Environment and Development 18 (4): 425-435.

Popp, David. 2011. "International Technology Transfer, Climate Change, and the Clean Development Mechanism." Review of Environmental Economics and Policy 5 (1): 131-152.

Schreurs, Miranda A. 2008. "From the Bottom Up: Local and Subnational Climate Change Politics." Journal of Environment and Development 17 (4): 343-355.

Schroeder, Miriam. 2009. "Varieties of Carbon Governance: Utilizing the Clean Development Mechanism for Chinese Priorities." Journal of Environment and Development 18 (4): 371-394.

Shalini Randeria. 2003. "Between Cunning States and Unaccountable Institutions: Social Movements and rights of Local Communities to Common Property Resources." WZB Discussion Paper Nr. SP IV 2003-502.

Sirohi, Smita. 2007. “CDM: Is It a 'Win-Win' Strategy for Rural Poverty Alleviation in India?" Climatic Change 84 (1): 91-110.

Tongia, Rahul. 2003. “The Political Economy of India Power Sector Reforms." Stanford University, Program on Energy and Sustainable Development, Working Paper 4.

Transparency International. 2005. India Corruption Study 2005. New Delhi: Centre for Media Studies.

Vuong, Quang H. 1989. "Likelihood Ratio Tests for Model Selection and Non-Nested Hypotheses." Econometrica 57 (2): 307-333. 


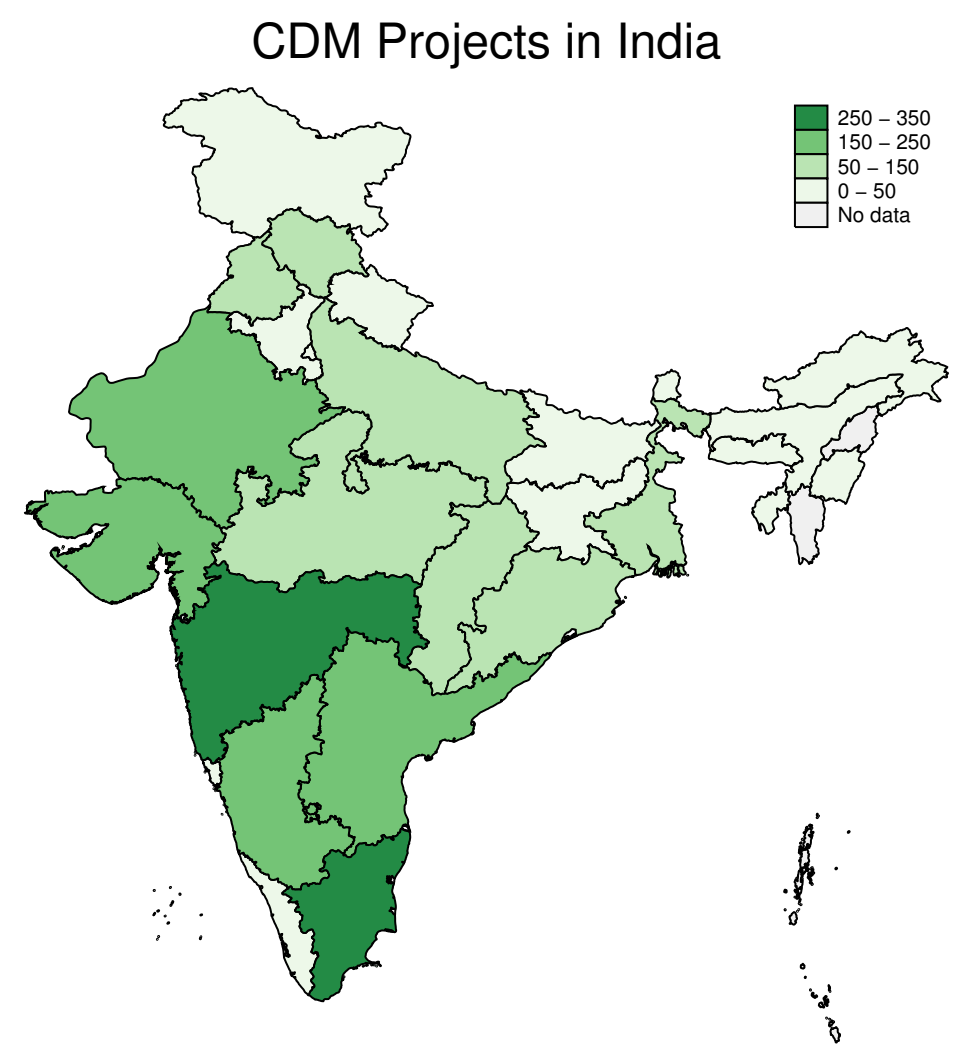

Figure 1: Total number of CDM projects in India, 2003-2011. 


\section{First Differences in Predicted Number of CDM Projects}

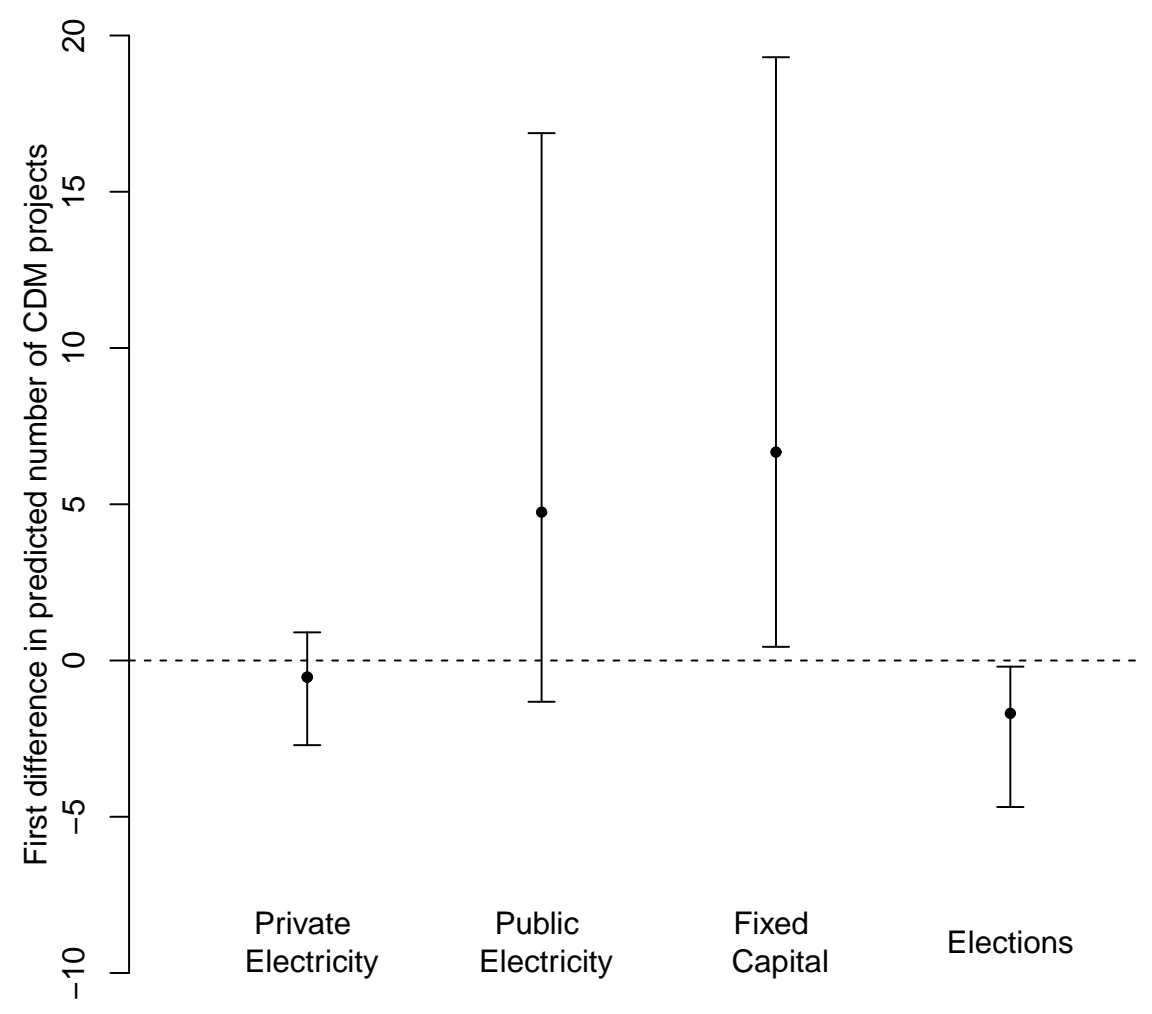

Figure 2: Substantive effects. For the three continuous variables, we consider a change from the mean to one standard deviation above the mean. For the elections dummy, we compare a change from zero to one. Error bars indicate 95\% confidence interval. 
Distribution of CDM projects by region, state, and year

\begin{tabular}{|c|c|c|c|c|c|c|c|c|c|c|c|}
\hline \multirow[t]{2}{*}{$\#$} & \multirow[t]{2}{*}{ State } & \multicolumn{9}{|c|}{ Years } & \multirow[t]{2}{*}{ Sum } \\
\hline & & 2003 & 2004 & 2005 & 2006 & 2007 & 2008 & 2009 & 2010 & 2011 & \\
\hline & Northern Zonal Council & & & & & & & & & & 357 \\
\hline 1 & Delhi & 0 & 0 & 0 & 0 & 3 & 2 & 3 & 3 & 1 & 12 \\
\hline 2 & Chandigarh & na & na & na & na & na & na & na & na & na & na \\
\hline 3 & Haryana & 0 & 0 & 0 & 3 & 5 & 7 & 7 & 6 & 4 & 32 \\
\hline 4 & Himachal Pradesh & 0 & 2 & 2 & 14 & 8 & 8 & 17 & 16 & 11 & 78 \\
\hline 5 & Jammu and Kashmir & 0 & 0 & 0 & 0 & 2 & 1 & 1 & 1 & 0 & 5 \\
\hline 6 & Punjab & 0 & 0 & 13 & 10 & 4 & 10 & 4 & 14 & 10 & 65 \\
\hline \multirow[t]{2}{*}{7} & Rajasthan & 0 & 1 & 23 & 14 & 9 & 6 & 20 & 43 & 49 & 165 \\
\hline & Central Zonal Council & & & & & & & & & & 307 \\
\hline 8 & Chhattisgarh & 0 & 0 & 11 & 21 & 17 & 12 & 8 & 7 & 15 & 91 \\
\hline 9 & Madhya Pradesh & 0 & 0 & 4 & 3 & 6 & 8 & 10 & 10 & 15 & 56 \\
\hline 10 & Uttarakhand & 0 & 0 & 0 & 8 & 10 & 6 & 7 & 6 & 6 & 43 \\
\hline \multirow[t]{2}{*}{11} & Uttar Pradesh & 0 & 0 & 12 & 35 & 16 & 25 & 7 & 14 & 8 & 117 \\
\hline & Eastern Zonal Council & & & & & & & & & & 166 \\
\hline 12 & Bihar & 0 & 0 & 1 & 2 & 3 & 0 & 0 & 1 & 2 & 9 \\
\hline 13 & Jharkhand & 0 & 0 & 1 & 1 & 4 & 2 & 1 & 3 & 2 & 14 \\
\hline 14 & Orissa & 0 & 0 & 6 & 7 & 15 & 12 & 13 & 11 & 8 & 72 \\
\hline \multirow[t]{2}{*}{15} & West Bengal & 0 & 0 & 11 & 8 & 14 & 9 & 9 & 9 & 11 & 71 \\
\hline & Western Zonal Council & & & & & & & & & & 543 \\
\hline 16 & Dadra and Nagar Haveli & na & na & na & na & na & na & na & na & na & na \\
\hline 17 & Daman and Diu & na & na & na & na & na & na & na & na & na & na \\
\hline 18 & Goa & 0 & 0 & 1 & 0 & 1 & 0 & 0 & 1 & 0 & 3 \\
\hline 19 & Gujarat & 1 & 0 & 14 & 22 & 26 & 56 & 34 & 34 & 61 & 248 \\
\hline \multirow[t]{2}{*}{20} & Maharashtra & 0 & 0 & 13 & 34 & 55 & 61 & 40 & 50 & 39 & 292 \\
\hline & Southern Zonal Council & & & & & & & & & & 736 \\
\hline 21 & Andhra Pradesh & 0 & 1 & 30 & 25 & 25 & 24 & 3 & 22 & 27 & 157 \\
\hline 22 & Karnataka & 0 & 3 & 26 & 38 & 28 & 38 & 39 & 23 & 33 & 228 \\
\hline 23 & Kerala & 0 & 0 & 1 & 0 & 5 & 6 & 4 & 3 & 1 & 20 \\
\hline 24 & Pondicherry & na & na & na & na & na & na & na & na & na & na \\
\hline \multirow[t]{2}{*}{25} & Tamil Nadu & 0 & 2 & 22 & 28 & 40 & 53 & 51 & 55 & 80 & 331 \\
\hline & Northeastern Zonal Coun & & & & & & & & & & 66 \\
\hline 26 & Arunachal Pradesh & 0 & 0 & 0 & 0 & 1 & 0 & 0 & 0 & 2 & 3 \\
\hline 27 & Assam & 0 & 0 & 0 & 3 & 2 & 4 & 1 & 2 & 2 & 14 \\
\hline 28 & Manipur & 0 & 0 & 1 & 0 & 1 & 0 & 13 & 14 & 12 & 41 \\
\hline 29 & Meghalaya & 0 & 0 & 0 & 1 & 0 & 0 & 1 & 1 & 0 & 3 \\
\hline 30 & Mizoram & na & na & na & na & na & na & na & na & na & na \\
\hline 31 & Nagaland & na & na & na & na & na & na & na & na & na & na \\
\hline 32 & Sikkim & 0 & 0 & 0 & 1 & 0 & 2 & 0 & 2 & 2 & 7 \\
\hline \multirow[t]{2}{*}{33} & Tripura & 0 & 0 & 0 & 0 & 0 & 0 & 0 & 1 & 0 & 1 \\
\hline & Total & 1 & 9 & 192 & 278 & 300 & 352 & 293 & 362 & 391 & 2,178 \\
\hline
\end{tabular}

Table 1: Number of CDM projects by region, state, and year, 2003-2011. 
Summary statistics

\begin{tabular}{lccccc}
\hline & & & & & \\
& count & mean & sd & min & max \\
\hline Total CDM projects & 207 & 9.63 & 14.06 & 0.00 & 80.00 \\
CDM projects (renewables) & 207 & 6.19 & 10.96 & 0.00 & 73.00 \\
CDM projects (non-renewables) & 207 & 3.43 & 4.81 & 0.00 & 26.00 \\
Private electricity capacity (log) & 207 & 3.49 & 3.25 & 0.00 & 8.56 \\
Public electricity capacity (log) & 207 & 7.85 & 1.23 & 5.01 & 9.70 \\
Fixed capital (log, interpolated) & 207 & 11.28 & 2.37 & 1.23 & 14.35 \\
Election year & 207 & 0.20 & 0.40 & 0.00 & 1.00 \\
Population (log, interpolated) & 207 & 10.16 & 1.31 & 6.40 & 12.20 \\
GDP per capita (1,000 rupee) (log) & 207 & 3.36 & 0.48 & 1.95 & 4.72 \\
Economic growth (pct) & 207 & 6.78 & 4.25 & -8.13 & 29.25 \\
Public debt (pct) & 207 & 35.85 & 13.74 & 14.20 & 77.46 \\
\hline
\end{tabular}

Table 2: Summary statistics for all CDM projects in India. The summary statistics are based on the sample that includes all of the control variables discussed above. 
Correlation matrix

\begin{tabular}{|c|c|c|c|c|c|c|c|c|c|c|c|}
\hline & (1) & $(2)$ & (3) & $(4)$ & (5) & (6) & (7) & (8) & (9) & (10) & (11) \\
\hline (1) Total CDM projects & 1.000 & & & & & & & & & & \\
\hline (2) CDM projects (renewables) & $0.956^{* * *}$ & 1.000 & & & & & & & & & \\
\hline (3) CDM projects (non-renewables) & $0.744^{* * *}$ & $0.516^{* * *}$ & 1.000 & & & & & & & & \\
\hline (4) Private electricity capacity $(\log )$ & $0.446^{* * *}$ & $0.394^{* * *}$ & $0.406^{* * *}$ & 1.000 & & & & & & & \\
\hline (5) Public electricity capacity (log) & $0.484^{* * *}$ & $0.417^{* * *}$ & $0.466^{* * *}$ & $0.413^{* * *}$ & 1.000 & & & & & & \\
\hline (6) Fixed capital (log, interpolated) & $0.437^{* * *}$ & $0.378^{* * *}$ & $0.416^{* * *}$ & $0.557^{* * *}$ & $0.842^{* * *}$ & 1.000 & & & & & \\
\hline (7) Election year & -0.052 & -0.044 & -0.050 & -0.023 & 0.011 & -0.028 & 1.000 & & & & \\
\hline (8) Population (log, interpolated) & $0.382^{* * *}$ & $0.311^{* * *}$ & $0.408^{* * *}$ & $0.300^{* * *}$ & $0.885^{* * *}$ & $0.725^{* * *}$ & 0.029 & 1.000 & & & \\
\hline (9) GDP per capita (1,000 rupee) (log) & $0.282^{* * *}$ & $0.291^{* * *}$ & $0.160^{*}$ & $0.373^{* * *}$ & -0.039 & $0.168^{*}$ & -0.035 & $-0.393^{* * *}$ & 1.000 & & \\
\hline (10) Economic growth (pct) & 0.093 & 0.098 & 0.049 & 0.072 & 0.106 & 0.095 & 0.109 & 0.074 & 0.115 & 1.000 & \\
\hline (11) Public debt (pct) & $-0.303^{* * *}$ & $-0.253^{* * *}$ & $-0.308^{* * *}$ & $-0.337^{* * *}$ & $-0.270^{* * *}$ & $-0.387^{* * *}$ & -0.032 & $-0.221^{* *}$ & $-0.370^{* * *}$ & $-0.178^{*}$ & 1.000 \\
\hline
\end{tabular}

Table 3: Correlation matrices for all CDM projects in India. The correlations are based on the sample that includes all of the the control variables discussed above. 
Main regression results

\begin{tabular}{lccccc}
\hline & $(1)$ & $(2)$ & $(3)$ & $(4)$ & $(5)$ \\
& Model & Model & Model & Model & Model \\
\hline Private electricity capacity (log) & -0.019 & -0.026 & -0.028 & -0.028 & -0.013 \\
& $(0.030)$ & $(0.031)$ & $(0.030)$ & $(0.030)$ & $(0.030)$ \\
Public electricity capacity (log) & 0.363 & $0.681^{*}$ & 0.470 & 0.483 & 0.467 \\
& $(0.244)$ & $(0.363)$ & $(0.495)$ & $(0.497)$ & $(0.451)$ \\
Fixed capital (log, interpolated) & $0.239^{* *}$ & $0.258^{* *}$ & $0.270^{* *}$ & $0.274^{* *}$ & $0.279^{* *}$ \\
& $(0.113)$ & $(0.113)$ & $(0.121)$ & $(0.122)$ & $(0.132)$ \\
Election year & $-0.236^{* *}$ & $-0.228^{* *}$ & $-0.209^{* *}$ & $-0.214^{* *}$ & $-0.211^{* *}$ \\
& $(0.105)$ & $(0.104)$ & $(0.101)$ & $(0.103)$ & $(0.100)$ \\
Population (log, interpolated) & & -0.322 & -0.116 & -0.142 & 0.144 \\
& & $(0.276)$ & $(0.464)$ & $(0.473)$ & $(0.484)$ \\
GDP per capita (1,000 rupee) (log) & & & 0.441 & 0.381 & 1.142 \\
& & & $(0.822)$ & $(0.847)$ & $(0.909)$ \\
Economic growth (pct) & & & & 0.004 & 0.008 \\
& & & & $(0.014)$ & $(0.014)$ \\
Public debt (pct) & & & & & $0.032^{* * *}$ \\
& & & & & $(0.011)$ \\
Year Effects & Yes & Yes & Yes & Yes & Yes \\
Zonal Fixed-Effects & Yes & Yes & Yes & Yes & Yes \\
\hline Observations & 223 & 223 & 218 & 217 & 207 \\
\hline S & & & & & \\
\hline
\end{tabular}

Standard errors in parentheses

Dependent Variable in Model (1) to (5): Total Number of CDM Projects.

${ }^{*} p<0.10,{ }^{* *} p<0.05,{ }^{* * *} p<0.01$

Table 4: Main regression results from random effects count model. 
Main regression results for renewable CDM projects

\begin{tabular}{lccccc}
\hline & $(1)$ & $(2)$ & $(3)$ & $(4)$ & $(5)$ \\
& Model & Model & Model & Model & Model \\
\hline Private electricity capacity (log) & 0.013 & 0.008 & -0.002 & 0.002 & 0.011 \\
& $(0.043)$ & $(0.044)$ & $(0.043)$ & $(0.043)$ & $(0.041)$ \\
Public electricity capacity (log) & 0.269 & 0.596 & 0.423 & 0.488 & 0.675 \\
& $(0.355)$ & $(0.521)$ & $(0.710)$ & $(0.694)$ & $(0.520)$ \\
Fixed capital (log, interpolated) & 0.119 & 0.123 & 0.170 & 0.203 & 0.111 \\
& $(0.155)$ & $(0.154)$ & $(0.174)$ & $(0.174)$ & $(0.152)$ \\
Election year & $-0.373^{* *}$ & $-0.367^{* *}$ & $-0.349^{* *}$ & $-0.397^{* *}$ & $-0.390^{* *}$ \\
& $(0.160)$ & $(0.159)$ & $(0.158)$ & $(0.165)$ & $(0.152)$ \\
Population (log, interpolated) & & -0.300 & -0.218 & -0.368 & 0.088 \\
& & $(0.352)$ & $(0.682)$ & $(0.668)$ & $(0.527)$ \\
GDP per capita (1,000 rupee) (log) & & & 0.064 & -0.387 & 0.862 \\
& & & $(1.367)$ & $(1.338)$ & $(0.942)$ \\
Economic growth (pct) & & & & 0.027 & $0.038^{*}$ \\
& & & & $(0.022)$ & $(0.021)$ \\
Public debt (pct) & & & & & $0.044^{* * *}$ \\
Year Effects & Yes & Yes & Yes & Yes & Yes \\
Zonal Fixed-Effects & Yes & Yes & Yes & Yes & Yes \\
\hline Observations & 223 & 223 & 218 & 217 & 207 \\
\hline S & & & & & \\
\hline
\end{tabular}

Standard errors in parentheses

Dependent Variable in Model (1) to (5): Number of Renewable CDM Projects.

${ }^{*} p<0.10,{ }^{* *} p<0.05,{ }^{* * *} p<0.01$

Table 5: Regression results from random effects count model for renewable CDM projects. 
Main regression results for non-renewable CDM projects

\begin{tabular}{|c|c|c|c|c|c|}
\hline & $\begin{array}{c}(1) \\
\text { Model }\end{array}$ & $\begin{array}{c}(2) \\
\text { Model }\end{array}$ & $\begin{array}{c}(3) \\
\text { Model }\end{array}$ & $\begin{array}{c}(4) \\
\text { Model }\end{array}$ & $\begin{array}{c}(5) \\
\text { Model }\end{array}$ \\
\hline Private electricity capacity (log) & $\begin{array}{l}-0.025 \\
(0.033)\end{array}$ & $\begin{array}{l}-0.026 \\
(0.033)\end{array}$ & $\begin{array}{l}-0.017 \\
(0.034)\end{array}$ & $\begin{array}{c}-0.019 \\
(0.034)\end{array}$ & $\begin{array}{l}-0.021 \\
(0.035)\end{array}$ \\
\hline Public electricity capacity (log) & $\begin{array}{c}0.614^{* *} \\
(0.243)\end{array}$ & $\begin{array}{l}0.753^{*} \\
(0.410)\end{array}$ & $\begin{array}{c}0.527 \\
(0.497)\end{array}$ & $\begin{array}{c}0.495 \\
(0.499)\end{array}$ & $\begin{array}{c}0.526 \\
(0.527)\end{array}$ \\
\hline Fixed capital (log, interpolated) & $\begin{array}{c}0.212 \\
(0.136)\end{array}$ & $\begin{array}{c}0.223 \\
(0.139)\end{array}$ & $\begin{array}{c}0.234 \\
(0.144)\end{array}$ & $\begin{array}{c}0.223 \\
(0.144)\end{array}$ & $\begin{array}{c}0.274 \\
(0.172)\end{array}$ \\
\hline Election year & $\begin{array}{l}-0.067 \\
(0.123)\end{array}$ & $\begin{array}{l}-0.064 \\
(0.123)\end{array}$ & $\begin{array}{c}-0.071 \\
(0.125)\end{array}$ & $\begin{array}{l}-0.061 \\
(0.125)\end{array}$ & $\begin{array}{l}-0.055 \\
(0.127)\end{array}$ \\
\hline Population (log, interpolated) & & $\begin{array}{l}-0.143 \\
(0.340)\end{array}$ & $\begin{array}{c}0.099 \\
(0.490)\end{array}$ & $\begin{array}{c}0.165 \\
(0.498)\end{array}$ & $\begin{array}{c}0.055 \\
(0.566)\end{array}$ \\
\hline GDP per capita (1,000 rupee) (log) & & & $\begin{array}{c}0.451 \\
(0.685)\end{array}$ & $\begin{array}{c}0.574 \\
(0.704)\end{array}$ & $\begin{array}{c}0.340 \\
(0.968)\end{array}$ \\
\hline Economic growth (pct) & & & & $\begin{array}{c}-0.014 \\
(0.016)\end{array}$ & $\begin{array}{l}-0.013 \\
(0.016)\end{array}$ \\
\hline Public debt (pct) & & & & & $\begin{array}{c}0.004 \\
(0.013)\end{array}$ \\
\hline Year Effects & Yes & Yes & Yes & Yes & Yes \\
\hline Zonal Fixed-Effects & Yes & Yes & Yes & Yes & Yes \\
\hline Observations & 223 & 223 & 218 & 217 & 207 \\
\hline
\end{tabular}

Standard errors in parentheses

Dependent Variable in Model (1) to (5): Number of Renewable CDM Projects.

${ }^{*} p<0.10,{ }^{* *} p<0.05,{ }^{* * *} p<0.01$

Table 6: Regression results from random effects count model for non-renewable CDM projects. 